\title{
Intended Versus Inferred Care After PET Performed for Initial Staging in the National Oncologic PET Registry
}

\author{
Bruce E. Hillner ${ }^{1}$, Anna N. Tosteson², Tor D. Tosteson², Qianfei Wang ${ }^{2}$, Yunjie Song ${ }^{2}$, Lucy G. Hanna ${ }^{3}$, and Barry A. Siegel ${ }^{4}$ \\ ${ }^{I}$ Department of Internal Medicine and the Massey Cancer Center, Virginia Commonwealth University, Richmond, Virginia; ${ }^{2}$ The \\ Dartmouth Institute for Health Policy and Clinical Practice, Geisel School of Medicine at Dartmouth, Lebanon, New Hampshire; \\ ${ }^{3}$ Center for Statistical Sciences, Brown University, Providence, Rhode Island; and ${ }^{4}$ Division of Nuclear Medicine, Mallinckrodt \\ Institute of Radiology and the Siteman Cancer Center, Washington University School of Medicine, St. Louis, Missouri
}

The National Oncologic PET Registry (NOPR) collected data on intended management before and after PET in cancer patients. We have previously reported that PET was associated with a change in intended management of about one third of patients and was consistent across cancer types. It is uncertain if intended management plans reflect the actual care these patients received. One approach to assess actual care received is using administrative claims to categorize the type and timing of clinical services. Methods: NOPR data from 2006 to 2008 were linked to Medicare claims for consenting patients aged 65 y or older undergoing initial-staging PET scanning for bladder, ovarian, pancreatic, small cell lung, or stomach cancers. We determined the $60-d$ agreement between claimsinferred care and NOPR treatment plans. Results: Patients $(n=$ $4,661)$ were assessed, and $30 \%-52 \%$ had metastatic disease. Planned treatments were about two-thirds monotherapy, of which $46 \%$ was systemic therapy only, and one-third combinations. Claims paid by $60 \mathrm{~d}$ confirmed the NOPR plan of any systemic therapy, radiotherapy, or surgery in $79.3 \%, 64.7 \%$, and $63.6 \%$, respectively. Single-mode plans were much more often confirmed: systemic therapy in more than $85 \%$ of patients with ovarian, pancreatic, and small cell lung cancers and surgery in more than $73 \%$ of those with bladder, pancreatic, and stomach cancers. Intended combination treatments had claims for both in only $28 \%$ of patients receiving surgery-based combinations and in 55\% receiving chemoradiotherapy. About $90 \%$ of patients with NOPRplanned systemic therapy had evaluation or management claims from a medical oncologist. An age of less than $75 \mathrm{y}$ was associated more often with confirmation of chemotherapy, less often for radiotherapy but not with confirmation of surgery. Performance status or comorbidity did not explain confirmation rates within action categories, but confirmation rates were higher if the referrer specialized in the planned treatment. Conclusion: Claims confirmations of NOPR intent for initial staging were widely variable but were higher than previously reported for restaging PET, suggesting that measuring change in intended management is a reasonable method for assessing the impact diagnostic tests have on actual care.

Key Words: positron emission tomography; cohort studies; Medicare; medical record linkage; health services research; neoplasm staging

J Nucl Med 2013; 54:2024-2031

DOI: 10.2967/jnumed.113.123430

Received Mar. 20, 2013; revision accepted May 30, 2013.

For correspondence or reprints contact: Bruce E. Hillner, 1101 E. Marshall St.,

Rm. 7013 (Sanger Hall), Virginia Commonwealth University, Richmond, VA 23298.

E-mail: Hillner@vcu.edu

Published online Nov. 12, 2013.

COPYRIGHT (C) 2013 by the Society of Nuclear Medicine and Molecular Imaging, Inc.
$\mathbf{O}$ ptimal care for a patient with a newly diagnosed solid tumor has evolved into a complex, intertwined series of steps often involving multispecialty teams. Advanced medical imaging has an important role in establishing the initial stage and usually precedes definitive treatment (1).

Since 2001, PET, alone or integrated with CT (hereinafter together referred to as PET), using ${ }^{18} \mathrm{~F}$-FDG has been a service covered by Medicare (and most commercial insurers) for the initial staging of patients with non-small cell lung, colorectal, esophageal, and head and neck cancers, as well as lymphoma and melanoma, and its use has grown rapidly $(2,3)$. However, at that time, PET remained a noncovered service for most less-common cancer types.

In 2005, Centers for Medicare and Medicaid Services (CMS) announced a novel coverage mechanism, "coverage with evidence development (CED)," for the otherwise noncovered cancer types and indications in conjunction with prospective data collection within a registry (4). In response to the CED requirements, the National Oncologic PET Registry (NOPR) was created and opened for accrual in 2006 (5). We have previously reported results of the impact of PET on intended management by collecting prospective questionnaire data before and after PET stratified by testing indication and by cancer type $(6,7)$.

Limitations of the NOPR data include the following: change in planned management is only a surrogate for actual health outcomes and the care actually delivered is not documented $(8,9)$. Although there are numerous studies of adherence to oral cancer therapies, there are few series that address the concordance between recommended actions and actual care initiated $(10,11)$. If the concept of "change in intended management" should be carried forward and applied to future assessments of new imaging techniques, this decision is likely to be influenced by evidence of confirmation of actual actions or outcomes.

One common approach is to use and analyze administrative claims to document the patterns of use and timing of various clinical services. Oncology has been the subject of wide-ranging evaluations using SEER (Surveillance, Epidemiology, and End Results) cancer registry data and Medicare claims (12).

In this report, we linked NOPR participant's individual identifiers with their Medicare claims. The analytic approach to this linked dataset was stratified by the clinical indication for PET: initial staging, restaging, or treatment monitoring. Here we report on intended plan initiation after PET used for staging of newly diagnosed cancer. We have previously reported results for restaging that found moderate agreement between intended and claimsinferred care (13). We hypothesized that confirmation rates would 
be higher than for restaging because prior treatments would not be a factor. In addition, we assessed patterns of delayed treatment and secondary decision points for combination therapies.

\section{MATERIALS AND METHODS}

NOPR is a prospective data registry (ClinicalTrials.gov \#NCT00868582); its operational details, human subject protection procedures, and PET's impact on intended management were previously reported $(6,14)$. In brief, the PET facility collects referring physician responses on pre-PET and post-PET forms. The pre-PET form collects the testing indication, cancer type, working stage, performance status, and the referring physician's plans if PET were not available. After PET, the referrer records an estimate of the patient's tumor stage and management plan in light of the PET findings.

\section{Claims Linkage}

We linked NOPR data from December 2006 through 2008 for consenting participants to their Medicare claim files by matching individual identifiers (date of birth, social security number, and sex). We limited our analysis to the 7 most frequent cancer types within NOPR. As previously noted, PET was a covered service for more common cancer types, such as non-small cell lung and colorectal cancers. We stratified our analyses by testing indication (initial staging, treatment monitoring, or restaging). In addressing initial staging, we excluded kidney and prostate cancer patients because of our prior work showing poor detection of oral chemotherapy claims for kidney cancer and explicit noncoverage of initial staging PET for prostate cancer in CMS's 2009 National Coverage Decision (15).

The analysis dataset of 4,661 was determined after the following exclusions: patients who were aged less than 65 y $(9.0 \%)$; who were health maintenance organization participants $(8.0 \%)$; or for whom we were unsuccessful in linking identifiers $(1.5 \%)$, if the registry and claim dates for PET differed by more than $7 \mathrm{~d}(2.0 \%)$, or if the postPET plan was "other treatment(s)" or "additional imaging" because of their low frequencies (1.5\% and $3.0 \%$, respectively).

\section{Management Categories}

Post-PET categories assessed were watching, biopsy, and treatment. Treatment categories were systemic therapy (chemotherapy or immunotherapy), radiotherapy, or surgery alone or in combination. For combination therapies, NOPR did not record their sequence or concurrence.

\section{Claims Definitions and Time Frame}

Supplemental Table 1 (supplemental materials are available at http://jnm.snmjournals.org) documents how we used administrative coding data to classify claims into inferred-care categories. The referring physician's impression of the patient's summary stage was abstracted from the post-PET form. We determined the Klabunde comorbidity index-derived from inpatient and outpatient physician claims in the 12 mo preceding the PET date (which approximates the date of diagnosis) — using a publically available SAS algorithm (16). The CMS provider part B taxonomy codes for physician specialty were used to categorize referring providers. If no specialty or nonphysician coding was found, then specialty was coded as other.

Although prompt treatment for newly diagnosed cancer is optimal, defining acceptable time windows either from initial diagnosis to primary surgical therapy or from surgical therapy to beginning adjuvant therapy is more problematic (17-19). The median time from diagnosis to surgery or starting neoadjuvant therapy in gastric and pancreatic cancer in 2003-2006 was between 20 and $25 \mathrm{~d}$ (18). In a SEER-Medicare analysis from 1999, $81 \%$ of patients started adjuvant therapy within $60 \mathrm{~d}$ of their surgery (19). A recent report from the National Comprehensive Cancer Network found an average time of 12 wk from diagnosis to start of adjuvant chemotherapy in early stage breast cancer (17). Because we did not have the NOPR participant's date of cancer diagnosis, we used our best estimate of $60 \mathrm{~d}$ after PET for the claims-inferred action window. We also explored an extension of the time window to $180 \mathrm{~d}$.

\section{Statistical Analysis}

The initial analyses treated the claims-inferred care as the reference standard to calculate measures of agreement between treatment plans and claims-inferred actual management, including positive predictive value (PPV), raw agreement, and $\kappa$ (chance-adjusted agreement) (20). For the treatments (systemic therapy, radiotherapy, or surgery), agreement was defined as claims for that type action within the interval, without considering other treatments; for plans with 2 or rarely 3 different therapy modes, we defined agreement as at least 1 claim paid for 2 types. The measures of agreement were computed separately by cancer type and compared using $\chi^{2}$ tests.

To assess the effect of patient, cancer, and provider factors in predicting agreement, separate logistic regression models were fit for patients with plans for any systemic therapy, radiotherapy, or surgery only. The outcome was the indicator of agreement with that element of the plan. Calculations were done with PROC LOGISTIC in Linux SAS version 9.2 (http://support.sas.com/documentation/cdl/en/statug/63033/ HTML/default/viewer.htm\#statug_logistic_sect004.htm). This analysis plan was similar to that used in our preceding work done assessing NOPR PET for restaging (13).

\section{RESULTS}

\section{Clinical Characteristics}

Table 1 summarizes the cancer type, age, performance status, comorbidity scores, referring physician specialty, and pre-PET plan for our 4,661-patient cohort.

The summary stage distribution varied across cancer types and sometimes differed from national SEER averages, suggesting that the NOPR patients were selectively referred for PET (21). When patients judged to have no evidence of residual disease (e.g., if PET was performed after a primary resection) are combined with those judged to have only local disease, NOPR patients with ovarian, pancreatic, and stomach cancers had modestly higher rates $(35 \%-45 \%)$ of local disease than their SEER cancer-specific averages. Metastatic disease at initial staging was judged present much more commonly for bladder cancer (35\%) than in SEER. Sixtyday mortality overall was $10 \%$ ranging from $5 \%$ in ovarian to $13 \%$ in small cell lung (SCL) and pancreatic cancers.

Referring physicians were identified as medical oncologists in slightly more than half of patients; were more than $10 \%$ surgeons in pancreatic and stomach cancer patients; and were more than $10 \%$ radiation oncologists in bladder, pancreatic, and SCL cases.

\section{NOPR Plan}

After PET, staging appeared to be clinically complete in $90 \%$ (i.e., only $10 \%$ had plans for imaging or biopsy). Excluding that $10 \%$ of patients, the intended plan was new or additional treatment in $82.9 \%$ of patients (range, $79 \%-91 \%$ ) and watching in $9.8 \%$ (Table 2). Modest frequency variations by cancer type were noted in the planned treatment (of any type), watching, or biopsy.

Planned treatments were single modality in about two thirds of patients and combination therapies in one third. The most common treatment plan was systemic therapy alone $(45.7 \%$; range, $35 \%-$ $69 \%$ ). Almost all combination-therapy patients had plans including systemic therapy, so that $78.4 \%$ (range, 69\%-92\%) had systemictherapy plans in their intended care. Radiotherapy was planned for 
TABLE 1

NOPR Cohort Clinical Characteristics for PET Imaging Performed for Initial Staging

\begin{tabular}{|c|c|c|c|c|c|c|}
\hline \multirow[b]{2}{*}{ Characteristic } & \multicolumn{6}{|c|}{ Cancer type } \\
\hline & Combined & Bladder & Ovarian & Pancreatic & $S C L$ & Stomach \\
\hline Patients in cohort $(n)$ & 4,661 & 1,178 & 309 & 1,250 & 752 & 1,172 \\
\hline \multicolumn{7}{|l|}{ Age $(y)$} \\
\hline Mean & 74.8 & 76.4 & 73.0 & 73.7 & 73.6 & 75.7 \\
\hline Interquartile range & $72-77$ & $71-81$ & $68-77$ & $68-78$ & $69-77$ & $70-81$ \\
\hline \multicolumn{7}{|l|}{$\begin{array}{l}\text { Eastern Cooperative Oncology Group } \\
\text { performance status (\%) }\end{array}$} \\
\hline 0 , asymptomatic & 26.6 & 32.8 & 28.2 & 23.4 & 19.7 & 27.7 \\
\hline 1 , symptomatic, fully ambulatory & 58.9 & 53.2 & 60.2 & 62.8 & 62.5 & 57.8 \\
\hline 2 or higher & 14.5 & 14.0 & 11.7 & 13.8 & 17.8 & 14.4 \\
\hline \multicolumn{7}{|l|}{ Post-PET summary stage (\%) } \\
\hline No residual disease & 6.8 & 9.0 & 14.9 & 4.5 & 0.9 & 8.8 \\
\hline Local only & 30.3 & 36.9 & 20.7 & 30.5 & 14.4 & 36.2 \\
\hline Regional (or nodal) diseases & 19.8 & 16.3 & 17.2 & 19.4 & 27.0 & 19.7 \\
\hline Metastatic disease, single site & 11.5 & 8.2 & 8.7 & 15.5 & 13.4 & 10.0 \\
\hline Metastatic disease, multiple sites & 28.0 & 26.5 & 33.3 & 26.7 & 42.2 & 20.2 \\
\hline Not recorded & 3.6 & 3.1 & 5.2 & 3.4 & 2.1 & 5.1 \\
\hline \multicolumn{7}{|l|}{ Comorbidity index score (\%) } \\
\hline 0 & 36.3 & 36.3 & 55.3 & 37.8 & 25.0 & 37.0 \\
\hline 1 or 2 & 46.9 & 42.3 & 36.6 & 49.3 & 56.1 & 45.8 \\
\hline$\geq 3$ & 16.8 & 21.4 & 8.1 & 13.0 & 18.9 & 17.2 \\
\hline \multicolumn{7}{|l|}{ Referring physician specialty (\%) } \\
\hline Medical oncology & 55.1 & 55.9 & 57.0 & 54.9 & 54.9 & 54.2 \\
\hline Internal medicine ${ }^{\star}$ & 11.2 & 5.2 & 5.8 & 9.8 & 19.8 & 14.4 \\
\hline Radiation oncology & 9.0 & 12.5 & 1.3 & 11.5 & 11.0 & 3.5 \\
\hline Surgery & 7.2 & 0.9 & 2.9 & 10.3 & 2.5 & 14.3 \\
\hline Urology & 3.5 & 13.7 & 0.3 & 0.1 & 0.0 & 0.1 \\
\hline Gynecology/gynecologic oncology & 1.5 & 0.3 & 19.7 & 0.2 & 0.0 & 0.2 \\
\hline Other & 12.5 & 11.5 & 12.9 & 13.1 & 11.7 & 13.3 \\
\hline 60-d post-PET mortality (\%) & 10.0 & 6.8 & 4.8 & 12.6 & 12.8 & 10.0 \\
\hline \multicolumn{7}{|l|}{ Pre-PET plan (\%) } \\
\hline Watching & 1.9 & 2.4 & 3.2 & 1.7 & 1.0 & 2.0 \\
\hline Additional imaging & 36.2 & 36.2 & 40.8 & 32.1 & 41.6 & 36.0 \\
\hline Biopsy & 8.0 & 9.5 & 6.8 & 9.6 & 4.8 & 7.2 \\
\hline Treatment & 53.9 & 52.0 & 49.2 & 56.6 & 52.7 & 54.9 \\
\hline
\end{tabular}

one third of patients, usually in combination with chemotherapy or surgery. Surgery plans were equally split between surgery only or surgery plus chemotherapy or radiotherapy. Surgery was planned most frequently in stomach cancer $(48 \%)$ as opposed to $20 \%$ of bladder, ovarian, and pancreatic cancer patients.

\section{0-Day Agreement}

Table 3 shows the agreement measures by cancer type for NOPRintended treatments - any systemic therapy, radiotherapy, or surgeryand claims-inferred actions at $60 \mathrm{~d}$.

For any systemic therapy, the combined PPV was $79.3 \%$ ranging by type from more than $86 \%$ in ovarian and SCL, and more than $79 \%$ in bladder, to only $68 \%$ in stomach cancer. For plans of any radiotherapy, the combined PPV was $64.7 \%$, with only modest differences between cancer types. Plans for any surgery had a PPV of $71.4 \%$ in stomach cancer and ranged between $50 \%$ and $60 \%$ in the other cancer types.

In aggregate, raw agreement between NOPR plans and claims at $60 \mathrm{~d}$ was $74.1 \%$ for any systemic therapy, $80.8 \%$ for any radiotherapy, and $77.9 \%$ for any surgery. Kappas were 0.40 for systemic therapy, 0.53 for radiotherapy, and 0.43 for surgery.
In addition to imperfect PPVs, raw agreement was affected by claims, likely capturing a second decision point. For example, in patients with intended surgery-only plans, there were claims for both surgery and systemic therapy in $19 \%$ of bladder, $30 \%$ of stomach, and $38 \%$ of pancreatic cancer patients, likely reflecting appropriate care after surgical staging. Conversely, many systemic therapy-only plans likely also represented neoadjuvant intent with a deferred surgery decision. In pancreatic cancer, $20 \%(n=105)$ of patients with chemotherapy-only plans had surgery and chemotherapy claims at $60 \mathrm{~d}$.

\section{Single vs. Combination Therapy and Time Window}

Table 4 shows results of extending the time frame to $180 \mathrm{~d}$ for claims confirmation of mono- and combination therapies. The PPVs for chemotherapy only in pancreatic, ovarian, and SLC patients were noticeably high (85\%-91\%) at $60 \mathrm{~d}$, and extending the time window to $180 \mathrm{~d}$ increased PPVs by $1 \%-3 \%$. Radiotherapy was most frequently planned together with chemotherapy. In these cases, claims for both treatment types at $60 \mathrm{~d}$ were only 47\%-62\%; however, extending the time window to $180 \mathrm{~d}$ increased the confirmation index by $7 \%-16 \%$. Cases having surgery-only plans had surgical 
TABLE 2

NOPR-Intended Management Plan After PET for Initial Staging by Cancer Type

\begin{tabular}{|c|c|c|c|c|c|c|}
\hline \multirow[b]{2}{*}{ NOPR-intended management } & \multicolumn{6}{|c|}{ Cancer type } \\
\hline & All & Bladder & Ovarian & Pancreatic & SCL & Stomach \\
\hline Patients & 4,661 & 1,178 & 309 & 1,250 & 752 & 1,172 \\
\hline Watching & $457(9.8)$ & $149(12.6)$ & $41(13.5)$ & $99(7.9)$ & $38(5.1)$ & $130(11.1)$ \\
\hline Biopsy & $341(7.3)$ & $101(8.6)$ & $24(0.6)$ & $90(7.2)$ & $28(3.7)$ & $98(8.4)$ \\
\hline Treatment & $3,864(82.9)$ & $928(78.8)$ & $245(79.3)$ & $1,061(84.9)$ & $686(91.2)$ & $944(80.6)$ \\
\hline \multicolumn{7}{|l|}{ Treatment details* } \\
\hline Systemic therapy only & $1,767(45.7)$ & 387 (41.7) & $169(69.0)$ & $530(50.0)$ & 349 (50.9) & $332(35.2)$ \\
\hline Radiotherapy only & $250(6.5)$ & $111(12.0)$ & $6(2.4)$ & $64(6.0)$ & $41(6.0)$ & $28(3.0)$ \\
\hline Surgery only & $554(14.3)$ & $129(13.9)$ & $15(6.1)$ & $135(12.7)$ & $11(1.6)$ & $264(28.0)$ \\
\hline Combination therapies & $1,293(33.4)$ & $301(32.4)$ & $55(22.4)$ & $332(31.3)$ & $285(41.5)$ & $320(33.9)$ \\
\hline Plans with systemic therapy & $3,030(78.4)$ & $676(72.8)$ & $223(91.0)$ & $854(80.5)$ & $629(91.7)$ & $648(68.6)$ \\
\hline Plans with radiotherapy & $1,293(33.5)$ & 337 (36.3) & $23(9.4)$ & $362(34.1)$ & $321(46.8)$ & $250(26.5)$ \\
\hline Plans with surgery & $1,031(26.7)$ & $248(26.7)$ & $57(23.3)$ & $242(22.8)$ & $26(3.8)$ & $458(48.5)$ \\
\hline
\end{tabular}

*Plans with therapy are sum of plans with single or combination therapy.

Data in parentheses are percentages.

claims at $60 \mathrm{~d}$ in $80 \%$ of stomach and $74 \%$ of bladder or pancreatic cancers. By $180 \mathrm{~d}$, surgery claims increased an additional $16 \%$ in bladder and $6 \%$ in pancreatic or stomach cancer patients.

The lowest rates and widest variation with time were found in confirming claims with surgery plus other treatments. By $60 \mathrm{~d}$, claims for surgery plus chemotherapy or radiotherapy ranged from $23 \%$ to $36 \%$ in bladder, stomach, and pancreatic cancers. However, by $180 \mathrm{~d}$, combined claims increased to $51 \%-61 \%$.

Although extending action windows to $180 \mathrm{~d}$ tended to increase agreement with explicitly planned actions, it had the opposite ef- fects for unplanned actions: by $180 \mathrm{~d}$, more actions occur that were absent in the NOPR plan. For instance, the status of no chemotherapy by plan matched to claims $71.6 \%$ over $30 \mathrm{~d}$, but this dropped to $42.5 \%$ over $180 \mathrm{~d}$. Correspondingly, the $\kappa$ statistic declined from 0.42 to 0.29 , from a fair to a poor level of agreement.

\section{Specialist Claims}

Using the provider specialty codes, we explored whether patients had evaluation and management (E\&M) claims from the specialist associated with the intended treatment, even if therapy

TABLE 3

Agreement Measurements by Type of Intended Therapy at 60 Days After PET

\begin{tabular}{|c|c|c|c|c|c|c|c|}
\hline \multirow[b]{2}{*}{$\begin{array}{l}\text { Post-PET planned therapy } \\
\text { and cancer type }\end{array}$} & \multirow[b]{2}{*}{$\begin{array}{l}\text { NOPR } \\
\text { plan }(n)\end{array}$} & \multicolumn{2}{|r|}{ PPV } & \multicolumn{2}{|c|}{ Raw agreement } & \multicolumn{2}{|r|}{ Kappa } \\
\hline & & $\%$ & $\begin{array}{l}95 \% \text { confidence } \\
\text { interval }\end{array}$ & $\%$ & $\begin{array}{l}\text { 95\% confidence } \\
\text { interval }\end{array}$ & к & $\begin{array}{l}95 \% \text { confidence } \\
\text { interval }\end{array}$ \\
\hline \multicolumn{8}{|l|}{ Any systemic therapy } \\
\hline All & 3,030 & 79.3 & $77.9-80.8$ & 74.1 & $72.7-75.4$ & 0.40 & $0.37-0.43$ \\
\hline Bladder & 676 & 79.0 & $75.9-82.1$ & 73.0 & $75.6-79.0$ & 0.42 & $0.36-0.48$ \\
\hline Ovarian & 223 & 86.1 & $81.6-90.6$ & 82.5 & $78.1-86.9$ & 0.52 & $0.41-0.64$ \\
\hline Pancreatic & 854 & 79.3 & $76.6-82.0$ & 72.8 & $70.3-75.4$ & 0.33 & $0.27-0.39$ \\
\hline SCL & 629 & 89.5 & $87.1-91.9$ & 83.8 & $81.2-86.5$ & 0.34 & $0.24-0.43$ \\
\hline Stomach & 648 & 67.6 & $64.0-71.2$ & 67.6 & $64.8-70.4$ & 0.34 & $0.29-0.40$ \\
\hline \multicolumn{8}{|l|}{ Any radiation } \\
\hline All & 1,293 & 64.7 & $62.1-67.3$ & 80.8 & $79.6-82.0$ & 0.53 & $0.51-0.56$ \\
\hline Bladder & 337 & 68.8 & $63.9-73.8$ & 83.3 & $81.1-85.5$ & 0.60 & $0.55-0.65$ \\
\hline Ovarian & 23 & 30.4 & $11.6-49.2$ & 91.6 & $88.4-94.8$ & 0.32 & $0.12-0.53$ \\
\hline Pancreatic & 362 & 70.2 & $65.5-74.9$ & 82.8 & $80.6-84.9$ & 0.59 & $0.54-0.64$ \\
\hline SCL & 321 & 69.2 & $64.1-74.2$ & 72.5 & $69.3-75.8$ & 0.44 & $0.38-0.51$ \\
\hline Stomach & 250 & 48.8 & $42.6-55.0$ & 79.0 & $76.5-81.4$ & 0.39 & $0.32-0.45$ \\
\hline \multicolumn{8}{|l|}{ Any surgery } \\
\hline All & 1,031 & 63.6 & $60.7-66.6$ & 77.9 & $76.7-79.2$ & 0.43 & $0.40-0.46$ \\
\hline Bladder & 248 & 56.9 & $50.7-63.0$ & 75.8 & $73.2-78.3$ & 0.36 & $0.30-0.42$ \\
\hline Ovarian & 57 & 52.6 & $39.7-65.6$ & 75.9 & 69.6-79.3 & 0.31 & $0.19-0.44$ \\
\hline Pancreatic & 242 & 59.9 & $53.7-66.1$ & 77.8 & $74.1-78.8$ & 0.39 & $0.33-0.45$ \\
\hline SCL & 26 & 50.0 & $30.8-69.2$ & 85.4 & $82.6-87.7$ & 0.15 & $0.06-0.24$ \\
\hline Stomach & 458 & 71.4 & $67.3-75.5$ & 75.7 & $70.3-75.4$ & 0.50 & $0.45-0.56$ \\
\hline
\end{tabular}

Agreement: sum of true-positive + true-negatives. 
TABLE 4

Impact of Time Interval After PET on Claims Confirmation (PPV) of Post-PET Plan

\begin{tabular}{|c|c|c|c|}
\hline Cancer type and treatment categories in Post-PET Plan & Patients $(n)$ & $\begin{array}{c}\text { Claims confirmed } \\
\text { at } 60 \mathrm{~d}(\%)\end{array}$ & $\begin{array}{c}\text { Claims confirmed } \\
\text { at } 180 \mathrm{~d}(\%)\end{array}$ \\
\hline \multicolumn{4}{|l|}{ Bladder } \\
\hline Chemotherapy/immunotherapy only & 387 & 81.1 & 84.2 \\
\hline Chemotherapy and radiotherapy & 182 & 62.1 & 69.2 \\
\hline Surgery only & 129 & 73.6 & 90.7 \\
\hline Surgery and (chemotherapy or radiotherapy) & 117 & 23.5 & 60.5 \\
\hline \multicolumn{4}{|l|}{ Pancreatic } \\
\hline Chemotherapy only & 530 & 85.3 & 88.7 \\
\hline Chemotherapy and radiotherapy & 225 & 53.8 & 69.8 \\
\hline Surgery only & 135 & 74.1 & 80.0 \\
\hline Surgery and (chemotherapy or radiotherapy) & 107 & 36.4 & 51.4 \\
\hline \multicolumn{4}{|l|}{ Stomach } \\
\hline Chemotherapy only & 332 & 69.6 & 78.2 \\
\hline Chemotherapy and radiotherapy & 126 & 47.6 & 61.9 \\
\hline Surgery only & 264 & 80.3 & 86.4 \\
\hline Surgery and (chemotherapy or radiotherapy) & 194 & 31.4 & 60.8 \\
\hline \multicolumn{4}{|l|}{ Ovarian } \\
\hline Chemotherapy only & 169 & 90.5 & 93.5 \\
\hline \multicolumn{4}{|l|}{ SCL } \\
\hline Chemotherapy only & 349 & 88.8 & 89.7 \\
\hline Chemotherapy and radiotherapy & 270 & 62.6 & 73.0 \\
\hline
\end{tabular}

Excluded plans with $<100$ patients.

claims were not found. This was true for medical oncology and chemotherapy.

Figure 1 shows that within $30 \mathrm{~d}$ most patients with chemotherapy planned had E\&M medical oncologist claims-even in the absence of paid chemotherapy claims. Overall, E\&M oncologist claims were found in $87 \%$ at $30 \mathrm{~d}$, rising to $92 \%$ at $60 \mathrm{~d}$. Almost all SCL patients having medical oncologist E\&M claims also had chemotherapy claims. In contrast, $24 \%$ of stomach cancer patients with chemotherapy plans had medical oncologist visits but no detected chemotherapy claims by $60 \mathrm{~d}$.

\section{Predictors}

The results when we assessed the impact of patient (age, performance status, comorbidity), cancer (type, summary stage), and referring provider (specialty, pre-PET plan) factors in a logistic regression model in predicting agreement by treatment type at $60 \mathrm{~d}$ are summarized in Table 5 (full details are provided in Supplemental Table 2).

Patients aged 75 y or less were associated with higher claims agreement for chemotherapy, slightly lower agreement for radiotherapy, and not associated for surgery.

The impact of stage varied by treatment type. Patients having local disease with plans for surgery had claims confirmation in $73 \%$ versus $53 \%$ in nodal/regional disease. Radiotherapy agreement rates were similar for local and nodal/regional disease at $72 \%$ and were markedly less commonly planned or confirmed for metastatic disease. Claims confirming chemotherapy plans did not differ among patients with nodal/regional, single-site, or multisite metastasis at about $82 \%-84 \%$ but were lower with local disease $(76 \%)$.

If the referring physician was the specialist providing the treatment type, there was much higher concordance for surgery or radiotherapy plans but minimal differences for medical oncologists and chemotherapy.

\section{DISCUSSION}

The NOPR management plan reflects the physician's intentions shortly after receiving the PET report and not necessarily the patient's agreement to the plan. Agreement between claims-inferred management (assuming these are complete and accurate) and the NOPR plan may be affected by patient treatment preferences revealed in subsequent consultations or the physician's level of commitment to his or her plan. Unexpected shifts in a patient's symptoms and clinical course could also impact the intended plans' feasibility. This analysis of 5 cancer types when PET was used as part of initial staging found claims-validated monotherapy plans in over three fourths of patients within $60 \mathrm{~d}$. However, for combination therapy, a 60-d window was too short to fully capture clinical actions inferred from claims analysis. One relevant NOPR data limitation was that the post-PET questionnaire did not document whether combination therapy plans were to be concurrent or sequential. Therefore, for sequential plans, it is likely that the decision to give the anticipated second therapy encompassed a further decision point

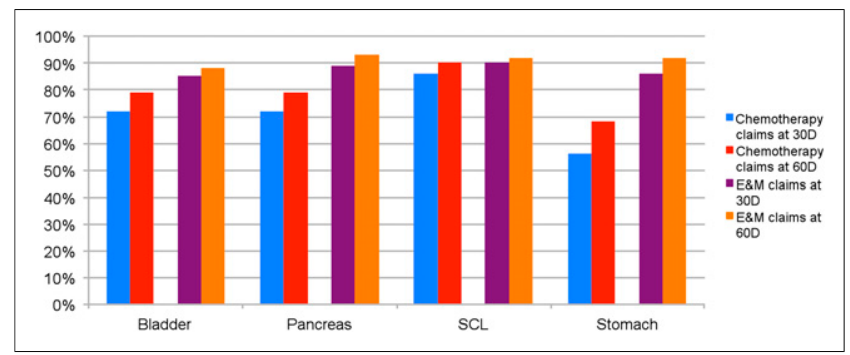

FIGURE 1. Frequency of chemotherapy claims and E\&M claims by cancer type among subjects for whom NOPR intended-management plan was chemotherapy. We excluded ovarian cancer because gynecologic oncologists in addition to medical oncologists often give systemic therapies. 
TABLE 5

Factors Associated with Agreement of Treatment Plan and Claims for Treatment

\begin{tabular}{|c|c|c|c|c|c|c|}
\hline \multirow[b]{2}{*}{ Factors } & \multicolumn{2}{|c|}{ Chemotherapy $(n=3,030)$} & \multicolumn{2}{|c|}{ Radiotherapy $(n=1,293)$} & \multicolumn{2}{|c|}{ Surgery $(n=1,031)$} \\
\hline & Agreement & $P$ & Agreement R & $P$ & Agreement & $P$ \\
\hline Unadjusted & 79.3 & & 64.7 & & 63.6 & \\
\hline \multicolumn{7}{|c|}{ Adjusted agreement range ${ }^{\star}$} \\
\hline Age $\leq$ or $>75$ y & $75.5-84.7$ & $<0.0001$ & $65.4-71.7$ & 0.007 & $64.8-66.2$ & 0.846 \\
\hline Performance status & $77.2-82.6$ & 0.14 & $66.0-69.8$ & 0.744 & $57.7-68.8$ & 0.019 \\
\hline Comorbidity & $80.0-81.9$ & 0.604 & $65.3-71.5$ & 0.194 & $61.7-68.4$ & 0.197 \\
\hline Cancer type & $69.2-87.1$ & $<0.0001$ & $30.9-77.9$ & $<0.0001$ & $57.2-72.5$ & $<0.0001$ \\
\hline Stage & $70.5-84.0$ & 0.001 & $47.6-73.2$ & $<0.0001$ & $43.8-72.8$ & $<0.0001$ \\
\hline Specialty & $70.2-80.9$ & 0.001 & $25.7-89.4$ & $<0.0001$ & $57.3-82.4$ & $<0.0001$ \\
\hline Pre-PET plan & $74.0-83.4$ & 0.178 & $67.8-83.7$ & 0.803 & $60.0-72.8$ & 0.065 \\
\hline
\end{tabular}

*Logistic regression was used to assess factors affecting proportion of individual plans agreeing with subsequent claims. Factor categories assessed were age $(<75,>75 \mathrm{y})$, performance status $(0,1, \geq 2)$, comorbidity $(0,1$ or $2,3+)$, cancer type (bladder, ovarian, pancreatic, SCL, stomach), provider specialty (medical oncology, gynecology, internal medicine, radiation oncology, surgery, and other), and pre-PET plan (image, biopsy, treatment, watch). On basis of logistic regression model, adjusted percentage agreements were calculated for each category and range calculated.

Complete details of individual factor agreements are available in Supplemental Table 2.

dependent on reassessment. For combined chemoradiotherapy plans, claims for both therapies increased by over $10 \%$ using a $180-$ vs. $60-d$ window. A second decision point was even more likely with surgery-based combination therapies where the chemotherapy sequencing was not specified (neoadjuvant vs. adjuvant).

Although this study uses as its starting point the unverified NOPR plan data and claims-inferred actions as the actual care, it is notable that there is no gold standard for the study design under which maximum concordance between plan and execution occurs and how high that concordance is. A more ideal design might involve a structured interview with each physician after PET once a care plan is established with the patient, documenting nuances of the plan, and a manual chart or electronic record review. Additionally, one might also collect information on patient perspective-after initial post-PET clinical consultation.

Outside oncology, there are many examples in surgical randomized trials showing that actual delivery rates of randomly assigned therapy are often substantially different from intention to treat. For example, 2 y after treatment assignment for lumbar spinal stenosis, $43 \%$ had surgery after being assigned nonsurgical treatment and only $67 \%$ completed assigned surgery (22). In coronary artery disease trials, crossover from medical therapy to surgical intervention occurs in $10 \%-20 \%$ of patients and surgical refusal in $2 \%-$ $10 \%(23,24)$. Crossover in abdominal aortic aneurysm trials are even higher (25). Thus, even if our plan and execution data points were obtained by more resource-intensive methodologies, it is unlikely that high (e.g., >90\%) agreement would occur.

There is a substantial, growing literature addressing the desire of cancer patients for information and participation in decision making in their care $(26,27)$. These studies have predominantly addressed preference-based primary therapy decisions in breast and prostate cancer. In general, older patients and those with metastatic cancers deferred more to physician recommendations $(26,28)$. To the best of our knowledge, few studies address discrepancies between physician plan, patient preference, and actual therapy received, factors that may explain some observed differences in intended versus claims-inferred management. One notable report is CanCORS, which assessed over 5,000 newly diagnosed lung or colorectal cancer patients, one fifth presenting with metastatic disease; $24 \%$ of CanCORS patients did not receive the treatment discussed (26,28).

Agreement studies within cancer registries focus on registry classification accuracy either when an independent record reabstraction (29) is made or when registry treatments are compared with claims-inferred care. Since 2000, numerous SEER-Medicare linkage reports have assessed claims completeness in identifying chemotherapy type (30-32), surgery (33), and radiation (34). Most studies did not focus on the claims' temporal accuracy. Since 2004, SEER guidelines require that all information be gathered through completion of first-course surgery or be available within 4 mo of diagnosis in the absence of disease progression (29). Our analysis shows that a 60-d window is likely too narrow for assessing planned treatment completion, particularly in patients with less-aggressive, local disease and for combination therapies. However, lengthening this window may also result in false-positives if claims are made for reasons not closely associated with the original post-PET plan (e.g., unplanned treatment at 3-6 mo for unexpectedly aggressive metastatic disease).

Two recent reports provide some context for our findings. In a comparison of Medicare administrative claims against clinical trial data (as a reference standard), Lamont et al. assessed patient cohorts from 6 CALGB first-line chemotherapy trials in breast, colorectal, and lung cancer (30). They found that $78 \%$ of claims correctly identified the drugs given and the correct treatment schedule. In a second study, Lund et al. reported National Cancer Institute Patterns of Care studies in 4 cancer types where SEER initial treatment plans were directly validated against hospital and outpatient records that were reabstracted for chemotherapy (35). They found that the claim sensitivities were time dependent, ranging from $36 \%-50 \%$ at 2 mo to $84 \%-96 \%$ at $6 \mathrm{mo}$.

Our analysis was not powered to, and did not attempt to, stratify patients by stage within each cancer type, and we did not assess whether either the planned or the claims-inferred management in each patient agreed with authoritative clinical practice guidelines. Our findings that about $90 \%$ of patients with an intended plan including chemotherapy had E\&M (office visit) claims from a medical oncologist within $60 \mathrm{~d}$ even in the absence of chemotherapy claims suggest appropriate consultation for informed de- 
cision making was available - that is, patients who did not receive chemotherapy did not fail to see an oncologist.

The above concerns should not divert attention from the primary clinical endpoint and findings that NOPR was designed to measure-does PET as part of initial cancer staging lead to a change in (intended) clinical management? We have previously reported that during the first $2 \mathrm{y}$ of NOPR data collection, PET was associated with a $40 \%$ change in intended management if additional imaging was a post-PET option or a $13 \%$ change if no benefit was assumed in cases where additional imaging was chosen. Using a design similar to that of the NOPR, Scott et al. from Australia have reported series involving smaller patient numbers (range, 71$129)$ and centers $(n=3-6)$ but with detailed medical record follow-up to assess intended versus actual management (36-38). They found that PET (without CT) used for initial staging of head and neck and esophageal cancer and lymphoma was associated with a 34\%-38\% change in intended management and that the agreement at 3-6 mo between the post-PET plan and actual care ranged from $53 \%$ in esophageal cancer to $74 \%$ in lymphoma and head and neck cancer. Our results from a national registry with little control over center-to-center data quality are quite similar.

We have previously noted that PET-associated changes in intended management would not always be beneficial (because PET has both false-negative and false-positive results) (14). Moreover, changes in intended actions have a presumed, but uncertain, relationship to more tangible health outcomes, such as progressionfree or overall survival (39). However, given the above limitations, we were gratified to observe that claims at $60 \mathrm{~d}$ confirmed chemotherapy plans in $90 \%$ of SCL cancer patients and surgery in $80 \%$ with stomach cancer, assuming that in most cases PET results were accurate and accepted contemporary treatment is beneficial.

\section{CONCLUSION}

If future evaluations of new imaging techniques are initiated under the CMS CED policy, there are lessons to be learned from the NOPR experience. For example, the type and extent of prior imaging or treatment are likely to impact the agreement rates between intended and actual care. Although refinements in granular detail of intended management plans (e.g., specific drugs, sequencing for combination therapies) warrant consideration, our results suggest that the principal future change should be at least 1 additional follow-up data collection point - to confirm the actual initiation or cessation of treatment or changes in the use of relevant diagnostic studies. Innovative study designs that allow for investigation of the patient's role as a factor in planned versus received care at preference-sensitive decisions points should be piloted. We hypothesize that differences in treatment urgency and acceptability likely explain discordance more than inaccurate assessment of physicians' intended plans. The inability to make inferences about the impact of diagnostic imaging on patient outcomes outside a randomized trial will remain. A modest greater time investment and energy of all parties (patients, referring physicians, interpreting physicians, and registry analysts) and an expanded informed consent will be needed to strengthen the value of diagnostic registries for comparative effectiveness research.

\section{DISCLOSURE}

The costs of publication of this article were defrayed in part by the payment of page charges. Therefore, and solely to indicate this fact, this article is hereby marked "advertisement" in accordance with 18 USC section 1734 . This study was supported by the National Cancer Institute Grand Opportunity Award RC2CA148259. No other potential conflict of interest relevant to this article was reported.

\section{REFERENCES}

1. Hillman BJ, Goldsmith JC. The Sorcerer's Apprentice: How Medical Imaging Is Changing Health Care. New York, NY: Oxford University Press; 2011.

2. Centers for Medicare and Medicaid Services. Decision Memo for Positron Emission Tomography (FDG) (CAG-0065N). Available at: http://www.cms.gov/medicarecoverage-database/details/nca-decision-memo aspx $?$ NCAId $=85 \&$ NcaName $=$ Positron +Emission + Tomography $+($ FDG $) \& b c=$ ACAAAAAACAAAAA $\% 83 D \%$ 83D\&. Accessed October 17, 2013.

3. Hillner BE, Tosteson AN, Song Y, et al. Growth in the use of PET for six cancer types after coverage by Medicare: additive or replacement? J Am Coll Radiol. 2012;9:33-41.

4. Centers for Medicare and Medicaid Services. National Coverage Determinations with Data Collection as a Condition of Coverage: Coverage with Evidence Development. Available at: http://www.cms.gov/Medicare/Coverage/DeterminationProcess/ Downloads/ced.pdf. Accessed October 17, 2013.

5. Hillner BE, Liu D, Coleman RE, et al. The National Oncologic PET Registry (NOPR): design and analysis plan. J Nucl Med. 2007;48:1901-1908.

6. Hillner BE, Siegel BA, Hanna L, et al. Impact of ${ }^{18} \mathrm{~F}$-FDG PET used after initial treatment of cancer: comparison of the National Oncologic PET Registry 2006 and 2009 Cohorts. J Nucl Med. 2012;53:831-837.

7. Hillner BE, Siegel BA, Shields AF, et al. Relationship between cancer type and impact of PET and PET/CT on intended management: findings of the National Oncologic PET Registry. J Nucl Med. 2008;49:1928-1935.

8. Levine MN, Julian JA. Registries that show efficacy: good, but not good enough. J Clin Oncol. 2008;26:5316-5319.

9. Tunis S, Whicher D. The National Oncologic PET Registry: lessons learned for coverage with evidence development. J Am Coll Radiol. 2009;6:360-365.

10. Hershman DL, Kushi LH, Shao T, et al. Early discontinuation and nonadherence to adjuvant hormonal therapy in a cohort of 8,769 early-stage breast cancer patients. J Clin Oncol. 2010;28:4120-4128.

11. Partridge AH, Avorn J, Wang PS, Winer EP. Adherence to therapy with oral antineoplastic agents. J Natl Cancer Inst. 2002;94:652-661.

12. Elena JW, Travis LB, Simonds NI, et al. Leveraging epidemiology and clinical studies of cancer outcomes: recommendations and opportunities for translational research. J Natl Cancer Inst. 2013;105:85-94.

13. Hillner BE, Tosteson TD, Tosteson AN, et al. Intended versus inferred management after PET for cancer restaging: analysis of Medicare claims linked to a coverage with evidence development registry. Med Care. 2013;51:361-367.

14. Hillner BE, Siegel BA, Liu D, et al. Impact of positron emission tomography/ computed tomography and positron emission tomography (PET) alone on expected management of patients with cancer: initial results from the National Oncologic PET Registry. J Clin Oncol. 2008;26:2155-2161.

15. Centers for Medicare and Medicaid Services. National Coverage Determination (NCD) for Positron Emission Tomography (PET) Scans (220.6). Available at: http://www.cms.gov/medicare-coverage-database/details/ncd-details.aspx?NCDId= $211 \&$ ncdver $=4 \&$ NCAId $=92 \&$ ver $=19 \&$ NcaName $=$ Positron + Emission + Tomography $+\& b c=$ BEAAAAAAIAAA $\&$. Accessed October 17, 2013.

16. Klabunde CN. SEER-Medicare Calculation of Comorbidity Weights. Available at: http://healthservices.cancer.gov/seermedicare/program/comorbidity.html. Accessed October 17, 2013.

17. McAuliffe PF, Danoff S, Shapiro SD, Davidson NE. Treatment for breast cancer: is time really of the essence? J Natl Cancer Inst. 2013;105:80-82.

18. Bilimoria KY, Ko CY, Tomlinson JS, et al. Wait times for cancer surgery in the United States: trends and predictors of delays. Ann Surg. 2011;253:779-785.

19. Hershman D, Hall MJ, Wang X, et al. Timing of adjuvant chemotherapy initiation after surgery for stage III colon cancer. Cancer. 2006;107:2581-2588.

20. Szklo M, Nieto F. Epidemiology: Beyond the Basics. 3rd ed. Sudbury, MA: Jones and Bartlett Publishers; 2014.

21. National Cancer Institute. Cancer Stat Fact Sheets SEER. Available at: http:// seer.cancer.gov/statfacts/html/urinb.html. Accessed October 17, 2013.

22. Weinstein JN, Tosteson TD, Lurie JD, et al. Surgical versus nonsurgical therapy for lumbar spinal stenosis. N Engl J Med. 2008;358:794-810.

23. Hirsch A, Windhausen F, Tijssen JG, et al. Diverging associations of an intended early invasive strategy compared with actual revascularization, and outcome in patients with non-ST-segment elevation acute coronary syndrome: the problem of treatment selection bias. Eur Heart J. 2009;30:645-654.

24. Velazquez EJ, Lee KL, Deja MA, et al. Coronary-artery bypass surgery in patients with left ventricular dysfunction. N Engl J Med. 2011;364:1607-1616. 
25. Buckley CJ, Rutherford RB, Diethrich EB, Buckley SD. Inherent problems with randomized clinical trials with observational/no treatment arms. J Vasc Surg. 2010;52:237-241.

26. Elkin EB, Kim SH, Casper ES, Kissane DW, Schrag D. Desire for information and involvement in treatment decisions: elderly cancer patients' preferences and their physicians' perceptions. J Clin Oncol. 2007;25:5275-5280.

27. Mandelblatt JS, Faul LA, Luta G, et al. Patient and physician decision styles and breast cancer chemotherapy use in older women: Cancer and Leukemia Group B Protocol 369901. J Clin Oncol. 2012;30:2609-2614.

28. Keating NL, Beth Landrum M, Arora NK, et al. Cancer patients' roles in treatment decisions: do characteristics of the decision influence roles? J Clin Oncol. 2010;28:4364-4370.

29. German RR, Wike JM, Bauer KR, et al. Quality of cancer registry data: findings from CDC-NPCR's Breast and Prostate Cancer Data Quality and Patterns of Care Study. J Registry Manag. 2011;38:75-86.

30. Lamont EB, Lan L. Sensitivity of Medicare claims data for measuring use of standard multiagent chemotherapy regimens. Med Care. March 14, 2012 [Epub ahead of print].

31. Lamont EB, Herndon JE 2nd, Weeks JC, et al. Criterion validity of Medicare chemotherapy claims in Cancer and Leukemia Group B Breast and Lung Cancer trial participants. J Natl Cancer Inst. 2005;97:1080-1083.

32. Liang SY, Phillips KA, Wang G, et al. Tradeoffs of using administrative claims and medical records to identify the use of personalized medicine for patients with breast cancer. Med Care. 2011;49:e1-e8.
33. Cooper GS, Virnig B, Klabunde CN, Schussler N, Freeman J, Warren JL. Use of SEER-Medicare data for measuring cancer surgery. Med Care. 2002;40:IV43-IV-48.

34. Smith BD, Pan I-W, Shih Y-CT, et al. Adoption of intensity-modulated radiation therapy for breast cancer in the United States. J Natl Cancer Inst. 2011;103: 798-809.

35. Lund JL, Sturmer T, Harlan LC, et al. Identifying specific chemotherapeutic agents in Medicare data: a validation study. Med Care. November 15, 2011 [Epub ahead of print].

36. Chatterton BE, Ho Shon I, Baldey A, et al. Positron emission tomography changes management and prognostic stratification in patients with oesophageal cancer: results of a multicentre prospective study. Eur J Nucl Med Mol Imaging. 2009;36:354-361.

37. Scott AM, Gunawardana DH, Bartholomeusz D, Ramshaw JE, Lin P. PET changes management and improves prognostic stratification in patients with head and neck cancer: results of a multicenter prospective study. J Nucl Med. 2008;49:15931600 .

38. Scott AM, Gunawardana DH, Wong J, et al. Positron emission tomography changes management, improves prognostic stratification and is superior to gallium scintigraphy in patients with low-grade lymphoma: results of a multicentre prospective study. Eur J Nucl Med Mol Imaging. 2009;36:347-353.

39. Staub LP, Lord SJ, Simes RJ, et al. Using patient management as a surrogate for patient health outcomes in diagnostic test evaluation. BMC Med Res Methodol. 2012;12:12. 